\title{
A EFETIVIDADE DO SISTEMA INTERAMERICANO DE DIREITOS HUMANOS NOS PAÍSES DO MERCOSUL
}

\author{
Fernanda Bernardo Gonçalves ${ }^{1}$
}

\section{RESUMO}

A proteção internacional dos Direitos Humanos é tema que integra os estudos de Direito Internacional Público já há algumas décadas. Nessa esteira, surgiram os sistemas regionais de proteção dos direitos humanos, os quais podem ter uma eficácia maior por atenderem às especificidades de suas regiões. O Sistema Interamericano é um deles, e possui dois instrumentos de controle: a Comissão Interamericana de Direitos Humanos, responsável por averiguar denúncias e encaminhar pareceres ao segundo órgão, a Corte Interamericana de Direitos Humanos, que deve proceder à investigação dos fatos e posteriormente julgá-los. Entretanto, se a situação no plano teórico parece resolvida, no plano prático observa-se que o Sistema não consegue sequer ser reconhecido pela população como um instrumento de defesa, quanto mais contribuir para assegurar o respeito aos direitos humanos nos países do continente americano. Tal situação é agravada pela controvérsia entre a aplicação do Direito Internacional face às normas de direito interno, pois, ainda que se consiga levar um caso de desrespeito aos direitos humanos para julgamento perante a Corte, sua decisão pode não ser cumprida porque configuraria um desrespeito à soberania nacional. $O$ âmbito de abrangência do presente trabalho restringe-se aos países do Mercosul. Muito embora o acordo firmado entre eles refira-se a aspectos comerciais de mútua cooperação, não há dúvidas de que, além das especificidades comerciais, tais países possuem realidades socioeconômicas muito próximas, o que já indica a necessidade de uma atuação conjunta no enfrentamento desses problemas.

\footnotetext{
${ }^{1}$ Acadêmica de Direito da Universidade Federal do Paraná. Pesquisadora do Núcleo de Estudos em Direito Internacional da UFPR, do Núcleo de Pesquisas em Direito Público do Mercosul da UFPR e do Programa Especial de Treinamento da Faculdade de Direito da UFPR.
}

Revista Brasileira de Direito Internacional, Curitiba, v.3, n.3, jan./jun.2006 


\section{ABSTRACT}

The international human rights protection is a subject which has been taken part into the studies of Public Internacional Law for some decades. With this conception, the regional systems of human rights protection have came out. They can have a wider efficacy because they can include the specificities of their regions. The Inter-American System is one of them, and it has two mechanisms of control: the Inter-American Comission of Human Rights, which is responsible for checking the denunciations and for sending opinions to the second organ, the Inter-American Court of Human Rights, which has to investigate the facts and laterly judge them. However, if, in a theorical place, the situation seems to be resolved, in the practical one it is possible to see that the System cannot even be recognized by the people as an instrument of defence, nor represent a contribution to guarantee the respect to the human rights in the countries of the American mainland. The situation is much more serious because of the controversy between the application of International Law in view of the internal law, so as even if someone achieve to take a case of a disregard of human rights to be judged on the Inter-American Court, its decision may not be obbeyed because it could represent an offence to the national sovereignty. The ambit of this article is restrictec to the countries which compose the Common Market of the South - Mercosul. Although the agreement signed among them had been only about commercial cooperation, there are no doubts that, in spite of the commercial specificities, these countries have social and economic realities very similar, what indicate the necessity of a joined action in the confront against these problems.

Palavras-chave: Direitos Humanos; Sistema Interamericano de Proteção aos Direitos Humanos; Mercosul.

Key Words: Human Rights; Inter-American System of Human Rights Protection; Common Market of South - Mercosul. 


\section{INTRODUÇÃO}

Falar em Direitos Humanos hoje é algo muito comum nos meios acadêmicos. É bastante difundida a idéia de que tais direitos são aqueles garantidos a todos os homens e mulheres pelo simples fato de pertencerem ao gênero humano. Fazem parte desse rol de direitos todos aqueles constantes das Declarações e Convenções dedicadas ao tema, bem como os direitos positivados nos diversos sistemas jurídicos sob a rubrica de "direitos fundamentais"2.

No entanto, por mais que aparentemente já esteja consolidada uma definição de direitos humanos, há ainda muita controvérsia acerca do tema ${ }^{3}$. E uma das questões a ser resolvida diz respeito à efetividade da proteção internacional desses direitos. Com efeito, a emergência dos mecanismos internacionais destinados à garantia do respeito aos direitos humanos representou um avanço significativo no que concerne à observância e promoção de uma vida mais justa e digna para todos. Nada obstante, a efetividade de tais mecanismos é ainda um devir, na medida em que carecem de aceitação por parte da maioria dos governos do planeta.

O Sistema Interamericano de Direitos Humanos é um desses mecanismos, destinado à guarda e promoção dos direitos humanos em todo 0 continente americano. No entanto, muitos pareceres da Comissão e muitas decisões da Corte não encontram aceitação e, conseqüentemente, cumprimento por parte dos países signatários do Pacto de São José, que instituiu o referido Sistema Regional. Investigar as razões desse paradoxo é o objetivo do presente artigo.

O âmbito de trabalho, entretanto, será restrito aos países integrantes do Mercado Comum do Sul - Mercosul, conjuntamente considerados, e mais especificamente ao Brasil. Muito embora as diferenças de índole cultural sejam claramente visíveis, é possível delimitar um campo comum de necessidades

\footnotetext{
${ }^{2}$ Concebendo-se uma relação de complementaridade entre os conceitos de "direitos humanos" e "direitos fundamentais".

3 Cf. FIORATI, Jete Jane; BREVIGLIERI, Etiene. Direitos humanos e jurisprudência internacional: uma breve análise das decisões da Corte Interamericana de Direitos Humanos, p. 277.
}

Revista Brasileira de Direito Internacional, Curitiba, v.3, n.3, jan./jun.2006 
dos povos desses países - Brasil, Argentina, Paraguai, Uruguai e, futuramente, Venezuela -, cujos esforços no sentido de minimiza-lás poderiam ser tomados conjuntamente, representando aqui os direitos humanos o principal desafio a ser enfrentado.

Assim, o artigo é estruturado em três partes. Na primeira, analisaremos a estrutura do Mercosul, bem como as possibilidades da instituição de uma política mútua de promoção dos direitos humanos. Na segunda, o foco é o Sistema Interamericano de Direitos Humanos. Na terceira, uma análise da realidade dos direitos humanos no Mercosul e a (in)efetividade do Sistema Interamericano nesses países, bem como apresentaremos uma proposta de cooperação do Mercosul para tentar reverter essa situação.

\section{A ESTRUTURA DO MERCOSUL}

O que hoje se denomina Mercosul pode ser considerado como uma tentativa de consolidação dos ideais de integração que se disseminaram pelo mundo após a II Guerra Mundial. Frise-se que essa integração prima por aspectos comerciais e econômicos, ao menos inicialmente, e não se conhece nenhum exemplo de união política, por mais que a União Européia pareça caminhar nesse sentido.

$\mathrm{Na}$ América Latina, esse processo mais amplo de integração, a despeito dos diversos tratados bilaterais de cooperação firmados pelos países, teve início em 1960, com a assinatura do Tratado de Montevidéu, instituindo a Associação Latino-Americana de Livre Comércio (ALALC), composta por onze países latino-americanos ${ }^{3}$, que pretendia criar uma zona de livre comércio a qual evoluiria para um mercado comum ${ }^{4}$. Essa tentativa fracassou principalmente devido à emergência de regimes autoritários na América latina, e à crise econômica generalizada dos anos $70^{5}$. Em 1980, esses mesmos países formaram a Associação Latino-Americana de Integração (ALADI), por

\footnotetext{
${ }^{4}$ Brasil, Argentina, Paraguai, Uruguai, Bolívia, Chile, México, Colômbia, Venezuela, Equador e Peru.

${ }^{5}$ Cf. ACCIOLY, Elizabeth. Mercosul e União Européia, p. 60-61.

${ }^{6} \mathrm{Cf}$. ACCIOLY, Elizabeth. Mercosul e União Européia, p. 60.
}

Revista Brasileira de Direito Internacional, Curitiba, v.3, n.3, jan./jun.2006 
meio de um novo Tratado de Montevidéu, com a finalidade de "promover o desenvolvimento econômico-social, harmônico e equilibrado da América latina"6. Esse bloco existe até os dias atuais, mas enfrenta grandes dificuldades, não apenas pelos propósitos grandiosos, como também pela existência, entre os próprios países da ALADI, de outros blocos regionais, como é o caso do Mercosul.

O Mercado Comum do Sul tem suas origens nos diversos tratados de cooperação Brasil-Argentina firmados nos anos 80. Com as negociações em curso para a consolidação de um mercado comum entre os dois países, Paraguai e Uruguai uniram-se aos parceiros e, em 1991, surgia o Mercosul, com a assinatura do Tratado de Assunção. Esse acordo regulava a chamada fase provisória do Mercosul, com a criação de uma zona de livre comércio entre seus integrantes ${ }^{7}$ e a previsão de tratamento diferenciado para as economias menos desenvolvidas de Paraguai e Uruguai, até a assinatura do Protocolo de Ouro Preto, em 1994, que estabelece a fase definitiva do bloco regional, propugnando por uma união aduaneira até a concretização de um mercado comum entre os países.

São membros associados ao Mercosul Chile, Bolívia, Peru, Equador e Colômbia, que em um futuro próximo devem passar a integrar o bloco. Recentemente, houve o anúncio de que a Venezuela, atualmente membro associado, passará a fazer parte do bloco como membro efetivo.

Vejamos de que maneira está estruturado o Mercosul, de acordo com o Protocolo de Ouro Preto. Seus órgãos estão divididos em dois grupos ${ }^{8}$ : os órgãos com função normativa e administrativa e os órgãos auxiliares. Do primeiro grupo, fazem parte o Conselho do Mercado Comum (CMC), órgão superior do Mercosul com a função de conduzir politicamente o processo de integração, o Grupo Mercado Comum (GMC), órgão executivo do bloco, e a Comissão de Comércio do Mercosul (CCM), cuja principal tarefa é a de velar pela aplicação dos instrumentos de política comercial comum; as Decisões do

\footnotetext{
${ }^{7}$ ACCIOLY, E. Mercosul e União Européia, p. 63.

${ }^{8}$ Fase já superada no Mercosul, cf. BAPTISTA, Luiz Olavo. O Mercosul, suas instituições e ordenamento jurídico, p. 47.

${ }^{9}$ Cf. BAPTISTA, Luiz Olavo. O Mercosul, suas instituições e ordenamento jurídico.
}

Revista Brasileira de Direito Internacional, Curitiba, v.3, n.3, jan./jun.2006 
CMC, as Resoluções do GMC e as Diretrizes da CCM são de observância obrigatória para os Estados-partes. Já os órgãos auxiliares são: a Secretaria Administrativa do Mercosul, os Comitês Técnicos, a Comissão Parlamentar Conjunta e o Foro Consultivo Econômico e Social. Este último, por ser de interesse ao presente estudo, será objeto de considerações mais à frente.

Uma comparação muito freqüente é a que se realiza entre Mercosul e União Européia, como se esta última devesse ser a fonte de inspiração para os governos dos integrantes do bloco. No entanto, a configuração de ambos os blocos é distinta, bem como seus objetivos. A União Européia surgiu em 1957, e apresenta hoje a forma de união econômica, inclusive com a adoção de uma moeda comum a quase todos os membros. Sua principal característica é a configuração supranacional, tendo seus órgãos uma feição independente dos países que a compõem, pois representam os interesses de toda a Comunidade, o que não ocorre no Mercosul. Aqui, há uma idéia de cooperação entre os membros, não havendo delegação de parte da soberania dos Estados em prol do todo comunitário. Os funcionários dos órgãos, em sua maioria, representam seus países, e a maior parte das decisões é tomada por consenso entre os governos.

Os objetivos do Mercosul são claramente comerciais e econômicos, como é possível depreender da análise do Tratado de Assunção e do Protocolo de Ouro Preto. Haveria espaço, então, para a inclusão de uma normatividade protetiva dos direitos humanos, tendo em vista a situação comum de desrespeito à pessoa humana? Ou, ao menos, de mecanismos para tornar efetivas em seus países-membros as normas já existentes e pelos quais todos se obrigaram internacionalmente?

Brecha para isso já existe. Em 1996, na X Reunião dos Presidentes do Mercosul, o Comunicado Conjunto do Conselho do Mercosul assim dispôs: "os presidentes reafirmaram sua plena adesão aos princípios e às instituições democráticas, ao estado de direito e ao respeito aos direitos humanos e às liberdades fundamentais" ". Neste ano, nos dias 19 e 20 de junho, aconteceu em Assunção a XXVIII Cúpula de Chefes de Estado do Mercosul, e um dos

${ }^{10}$ Apud ACCIOLY, E. Mercosul e União Européia. p. 69.

Revista Brasileira de Direito Internacional, Curitiba, v.3, n.3, jan./jun.2006 
assuntos principais tratados no encontro, que contava também com a presença dos países associados ao bloco, foi a questão da situação dos Direitos Humanos nos países do Mercado Comum, o que leva a crer que em breve medidas conjuntas de proteção podem ser definidas, representando mais um avanço na proteção à dignidade humana.

No entanto, uma política comum de promoção de direitos humanos não é tão simples de ser realizada. A estrutura do Mercosul, extremamente burocratizada e vinculada aos objetivos comerciais do bloco, dificilmente poderá efetivar tarefa de tal envergadura, a menos que sofra modificações profundas.

E uma delas pode ser a reformulação do Foro Consultivo Econômico e Social. Atualmente, ele reúne os setores sociais envolvidos com o processo de integração, tais como sindicatos, associações de empresários, etc. No entanto, possui função meramente consultiva, e seus pareceres não são vinculantes. Dessa forma, considerações relevantes, como por exemplo, um parecer acerca de direitos dos trabalhadores nos países do bloco, podem ser deixadas de lado em nome de propósitos puramente econômicos. A reorganização do Foro pode ser uma primeira forma de assegurar o respeito aos direitos sociais, que também representam uma vertente dos direitos humanos. Um pequeno passo já foi dado nessa direção, com a proposta de Declaração dos Direitos Econômicos e Sociais do Mercosul, apresentada em 2004.

Ressalte-se a dificuldade de se ultrapassar as metas meramente comerciais para se chegar à uma atuação conjunta em matéria de defesa de direitos dos cidadãos. No contexto da União Européia, que já ultrapassou a fase de mercado comum e hoje caminha para uma união política, a tarefa é mais fácil, visto haver uma organização supranacional cujas decisões são obrigatórias aos países-membros. Entretanto, não é preciso que se atinja tal nível de integração para que a proteção dos direitos humanos possa ser um objetivo do Mercosul.

Propõe-se neste artigo uma saída mais rápida para essa problemática. Que os países do Mercosul assumam o compromisso de respeitar e cumprir as disposições dos Tratados Internacionais de Direitos Humanos a que se 
obrigaram convencionalmente. Essa exigência poderia ser um dos requisitos para a adesão e a entrada de novos membros ao bloco. Um dos mecanismos de proteção internacional de direitos humanos aos quais todos os países do Mercosul estão vinculados é o Sistema Interamericano de Direitos Humanos. Nada obstante, suas recomendações e decisões carecem de cumprimento, uma das razões pelas quais nem o desenvolvimento econômico trazido pelo Mercosul poderá assegurar as condições básicas de existência digna dos cidadãos desses países.

Retomaremos essa questão na terceira parte do trabalho. Agora, passaremos à análise dos mecanismos de proteção aos direitos humanos constantes do Sistema Interamericano.

\section{O SISTEMA INTERAMERICANO DE DIREITOS HUMANOS}

A proteção internacional dos direitos humanos tornou-se assunto de grande preocupação da comunidade internacional especialmente após a Segunda Guerra Mundial, quando se buscou desenvolver um meio de impedir que as atrocidades cometidas contra populações inteiras pelo regime nazista pudessem se repetir. Dessa forma, em 1945, com o estabelecimento da Organização das Nações Unidas (ONU), surge a Carta da ONU, a qual coloca a promoção dos Direitos Humanos no âmbito internacional como um dos objetivos fundamentais da organização, a ser constantemente perseguido pelo Estados signatários. Em 1948, a Assembléia Geral da ONU aprovou a resolução conhecida como Declaração Universal dos Direitos Humanos, a qual, embora tenha sua força vinculante questionada por diversos doutrinadores, possui observância obrigatória para os Estados membros da comunidade internacional tanto por representar uma definição da menção aos direitos humanos na Carta da ONU quanto pelo fato de já poder ser considerada costume internacional ${ }^{11}$. Um dos órgãos da ONU, o Conselho Econômico e Social, é o responsável pela Comissão de Direitos Humanos, que auxilia o monitoramento da situação desses direitos no mundo. Diversas outras

${ }^{11}$ Cf. PIOVESAN, Flávia. Direitos Humanos e o Direito Constitucional Internacional.

Revista Brasileira de Direito Internacional, Curitiba, v.3, n.3, jan./jun.2006 
Convenções Internacionais de Direitos Humanos foram firmadas desde então no âmbito das Nações Unidas, as quais têm por finalidade a proteção da pessoa humana em todo o mundo. Por esse motivo, esse sistema desenvolvido pela ONU é chamado de Sistema Global.

Entretanto, para assegurar uma proteção mais eficaz no que tange à questão dos direitos do homem, surgiram os Sistemas Regionais, cuja abrangência está restrita à região geográfica onde o sistema foi estabelecido. Esses instrumentos são complementares, no sentido de que propiciar uma maior oportunidade aos ofendidos para buscar seus direitos. No dizer de Antonio Augusto Cançado Trindade: "tais instrumentos de proteção, de natureza e efeitos jurídicos distintos, ao se multiplicarem ao longo dos anos, tiveram o propósito e acarretaram a conseqüência de ampliar o alcance da proteção a ser estendida às supostas vítimas" ${ }^{\prime 12}$. No mundo, existem os sistemas europeu, interamericano e africano, sendo que em breve já devem estar implementados os sistemas árabe e asiático. Por interessar à temática deste trabalho, analisaremos apenas o Sistema Interamericano de Direitos Humanos.

Este sistema pertence à esfera da Organização dos Estados Americanos (OEA). A primeira demonstração de que o tema dos direitos humanos deveria fazer parte da cotidiano dos Estados do continente ocorreu em 1948, poucos meses antes da DUDH, com a Declaração Americana dos Direitos e Deveres do Homem. Mas o Sistema Interamericano somente foi estruturado em 1969, com a Convenção Americana de Direitos Humanos, mais conhecida como Pacto de San Jose. No entanto, é bom frisar que nem todos os membros da OEA são signatários dessa Convenção. Ela é complementada por dois Protocolos, de San Salvador (que especifica a proteção aos direitos sociais, culturais e econômicos) e Contra a Pena de Morte, e por diversas outras Convenções.

O Sistema Interamericano possui dois órgãos de monitoramento do cumprimento pelos Estados dos deveres impostos pela Declaração, pelas

\footnotetext{
${ }^{12}$ CANÇADO TRINDADE, Antonio Augusto. A proteção internacional dos direitos humanos, p. 1.
}

Revista Brasileira de Direito Internacional, Curitiba, v.3, n.3, jan./jun.2006 
Convenções e pelos Protocolos ${ }^{13}$ : a Comissão e a Corte Interamericana de Direitos Humanos.

A Comissão Interamericana de Direitos Humanos surgiu em 1960, por meio da Resolução III da Quinta Reunião de Consulta de Ministros das Relações Exteriores dos países Americanos. Sua sede fica em Washington, Estados Unidos. É composta por sete membros eleitos a título pessoal pela Assembléia da OEA para desempenharem suas funções por um período de quatro anos, podendo ser reeleitos apenas uma vez; essas pessoas não representam seus países de origem e não podem atuar nos casos em que estes estiverem sob investigação. Segundo o artigo 41 do Pacto de San Jose, a principal função da Comissão é promover a observância e a defesa dos direitos humanos, podendo, dentre outras atribuições, fazer recomendações aos Estados, solicitar informações, encaminhar relatórios à Assembléia geral da ONU, e examinar as petições individuais e as comunicações interestatais que contenham denúncias de desrespeito ao Pacto $^{14}$. A Comissão possui competência para investigar todos os Estados membros da OEA: se o Estado for signatário da Convenção Americana, é ela que será aplicada, mas se não o for, será aplicada a Declaração Americana dos Direitos e Deveres do Homem.

Já a Corte Interamericana de Direitos Humanos foi criada pelo Pacto de San Jose, mas sob a forma de cláusula facultativa, ou seja, para que um Estado se submeta a sua jurisdição é necessário, além da assinatura da Convenção, uma declaração dessa aceitação. Sua sede é em San Jose, na Costa Rica. Os juízes da Corte são em número de sete, sendo também eleitos a título pessoal pela Assembléia Geral da OEA para um mandato de seis anos, podendo ser reeleitos uma única vez; assim como na Comissão, os juízes não representam seus países, mas podem atuar nos casos em que seus Estados de origem estejam sub judice. Possui duas atribuições. A função consultiva refere-se à faculdade de, mediante solicitação dos Estados-partes da OEA ou de seus órgãos, emitir pareceres acerca da interpretação da Convenção

\footnotetext{
${ }^{13}$ Cf. FRIEDRICH, Tatyana Scheila. Sistema Interamericano de Proteção de Direitos humanos: a Comissão e a Corte Interamericana de Direitos humanos, p. 262: "A Declaração Americana (...) não é apenas uma declaração de direitos (...) ela estabelece também deveres correlatos a esses direitos".

${ }^{14}$ Cf. PIOVESAN, F. Direitos Humanos e o Direito Constitucional Internacional.
}

Revista Brasileira de Direito Internacional, Curitiba, v.3, n.3, jan./jun.2006 
Americana ou de outro Tratado de direitos humanos no âmbito interamericano. Já a função contenciosa representa a jurisdição propriamente dita, pela qual a Corte irá julgar os casos de violações dos direitos humanos no continente americano. Apenas a Comissão e os Estados que reconhecerem sua competência podem apresentar denúncias perante a Corte; o acesso direito dos indivíduos não é permitido, sendo seus representantes apenas assistentes da Comissão ${ }^{15}$.

O processo de reclamação individual diante de uma violação de direitos humanos perante a Comissão Interamericana somente poderá ser iniciado se o direito violado estiver contido na Declaração Americana, ou na Convenção ou de um dos outros Tratados complementares ${ }^{16}$. Além disso, o Estado denunciado deve ser signatário da Convenção. Diferentemente do sistema europeu, não apenas a vítima pode peticionar, como também grupos de pessoas e organizações não-governamentais de defesa dos direitos humanos ${ }^{17}$. Entretanto, é requisito essencial para a propositura de uma demanda que as vítimas sejam determináveis ${ }^{18}$. Não é preciso que as vítimas estejam representadas por advogados.

Outros três requisitos devem ser observados pelos peticionários. È necessário que haja o esgotamento dos recursos internos no Estado contra o qual se formula a denúncia. Isto porque a jurisdição internacional é subsidiária da interna, e se o caso ainda estiver pendente de decisão judicial é possível que exista resultado favorável à vítima, sem a necessidade de se recorrer ao Sistema Interamericano. No entanto, para utilizar a expressão de Cançado Trindade, há uma "flexibilização do requisito do prévio esgotamento de recursos internos"20. Não há essa exigibilidade se houver demora injustificada no andamento do processo ou se nem mesmo for garantido à vítima o acesso aos meios judiciais. Resumindo, é preciso que um esgotamento eficaz dos recursos internos.

\footnotetext{
${ }^{15}$ Cf. FRIEDRICH, T. S. Sistema Interamericano de Proteção de Direitos humanos. p. 266.

${ }^{16}$ Cf. ORGANIZAÇÃO DOS ESTADOS AMERICANOS/COMISSÃO INTERAMERICANA DE

DIREITOS HUMANOS (Orgs). Como apresentar petições no sistema interamericano, p. 3.

${ }^{17}$ Cf. FRIEDRICH, T. S. Sistema Interamericano de Proteção de Direitos humanos, p. 263.

${ }^{18} \mathrm{Cf}$. OEA/CIDH. Como apresentar petições no sistema interamericano., p. 6.

${ }^{20}$ CANÇADO TRINDADE, A. A. A proteção internacional dos direitos humanos, p. 19.
}

Revista Brasileira de Direito Internacional, Curitiba, v.3, n.3, jan./jun.2006 
Ademais, a petição deve ser encaminhada à comissão no prazo de seis meses a partir da data da notificação da decisão judicial definitiva do tribunal nacional a respeito do caso. Entretanto, se o esgotamento não for exigível, a petição deve ser apresentada em prazo razoável ${ }^{21}$.

Por fim, o caso em questão não deve ser objeto de apreciação por outro Tribunal ou organismo internacional, para que não ocorram soluções distintas para o mesmo caso. Aqui se verifica a compatibilização entre os diversos instrumentos de proteção internacional de direitos humanos, especialmente entre o sistema global da ONU e os diversos sistemas regionais no mundo.

Se a denúncia contiver todos os requisitos de admissibilidade, a Comissão solicitará maiores informações ao Estado denunciado. Se mesmo depois dos esclarecimentos prestados, a Comissão opinar pela continuidade do caso, tentar-se-á uma solução amistosa entre as partes. Se não se chegar a um acordo, a Comissão examinará o mérito do caso, e se concluir pela responsabilidade do Estado denunciado, ela fará recomendações para que cessem as violações ou para que as vítimas sejam reparadas. Todo este procedimento é secreto, e apenas o estado envolvido tem acesso ao conteúdo das recomendações. Se não houver o cumprimento delas, a Comissão pode, dentro de três meses, enviar o caso para julgamento na Corte, ou fixar um prazo para que o Estado as cumpra. Após o decurso desse prazo, se ainda persistirem as violações, a Comissão publicará as conclusões a respeito do caso em um relatório anual da OEA. Também podem ser solicitadas medidas cautelares para proteger o indivíduo que estiver na iminência de sofrer uma violação em seus direitos.

Se o caso for enviado à Corte Interamericana, apenas atuarão a Comissão e o Estado denunciado, conforme supra referido, sendo o representante legal da vítima, se houver, mero assistente da CIDH. Quando não houver na Corte um juiz nacional do Estado sub judice, pode ser designado um juiz ad hoc para acompanhar o caso ${ }^{22}$. Somente os Estados que reconhecerem a competência da Corte podem ser submetidos à sua jurisdição,

\footnotetext{
${ }^{21}$ OEA/CIDH. Como apresentar petições no sistema interamericano, p. 9.

${ }^{22}$ FRIEDRICH, T. S. Sistema Interamericano de Proteção de Direitos humanos, p. 266.
}

Revista Brasileira de Direito Internacional, Curitiba, v.3, n.3, jan./jun.2006 
mas esse reconhecimento pode ocorrer por uma declaração específica para o julgamento de uma determinada causa, se não houver aceitado a jurisdição da Corte quando da ratificação da Convenção Americana de Direitos Humanos.

Com relação á inacessibilidade direta do indivíduo à Corte, algumas breves considerações devem ser tecidas. O sistema europeu, após a edição do Protocolo oㅜ 11, com vigência a partir de 1998, passou a permitir que os particulares peticionassem diretamente perante a Corte Européia de Direitos Humanos, conferindo à Comissão o papel de assegurar a correta aplicação dos direitos contidos na Convenção Européia de Direitos humanos ${ }^{23}$. Pelo contrário, no sistema interamericano isso ainda não é possível. A necessidade de prévia apreciação pela Comissão ocasiona muitas vezes a demora do procedimento, causando ainda mais sofrimento às vítimas. Para que a proteção se dê de forma efetiva, imperioso se faz que, além de reconhecer a personalidade jurídica internacional dos indivíduos, reconheça-se a eles também a capacidade processual internacional. Nas palavras de Cançado Trindade:

\footnotetext{
“do locus standi in judicio dos indivíduos ante a Corte Interamericana há que evoluir rumo ao reconhecimento, mais adiante, do direito de os indivíduos demandarem os Estados Partes diretamente ante a futura Corte Interamericana, levando diretamente a esta última casos concretos (jus standi), como órgão jurisdicional único do sistema interamericano de proteção do porvir",24.
}

No sistema interamericano, existe ainda a possibilidade de comunicações interestatais, isto é, de um estado signatário da Convenção denunciar um outro Estado nessas condições por violação de direitos humanos. Entretanto, esta possibilidade está prevista sob a forma de cláusula facultativa, cabendo aos Estados declararem expressamente sua aceitação. Segundo Flávia Piovesan:

“(...) os Estados-partes podem declarar que reconhecem a competência da Comissão para receber e examinar comunicações em que um Estado-parte

\footnotetext{
${ }^{23}$ Cf. QUESADA POLO, Santiago. El convenio europeo de derechos humanos.

${ }^{24}$ CANÇADO TRINDADE, A. A. A personalidade jurídica e capacidade jurídicas do indivíduo como sujeito do Direito Internacional. p. 29.
}

Revista Brasileira de Direito Internacional, Curitiba, v.3, n.3, jan./jun.2006 
alegue que outro Estado-parte tenha cometido violação a direito previsto na Convenção. Para a adoção do mecanismo das comunicações interestatais, é necessário que ambos os Estados tenham feito declaração expressa reconhecendo a competência da Comissão para tanto" ${ }^{25}$.

Após essa explanação acerca da estrutura da Comissão e da Corte Interamericana de Direitos Humanos, voltemos à questão da necessidade de os países-membros do Mercosul estarem definitivamente e conjuntamente integrados ao sistema interamericano, a fim de assegurar a proteção e a promoção dos direitos da pessoa humana de forma integral e efetiva.

\section{A EFETIVIDADE DAS RECOMENDAÇÕES DA COMISSÃO E DAS DECISÕES DA CORTE NOS PAÍSES DO MERCOSUL}

Conforme já se disse acima, o escopo deste artigo é propugnar pela incorporação da temática dos direitos humanos como um objetivo do Mercosul, por meio do qual Brasil, Argentina, Paraguai, Uruguai, e possíveis futuros membros do bloco pudessem buscar conjuntamente formas de garantir 0 respeito aos direitos humanos na região, dadas as condições sócioeconômicas e histórico-culturais semelhantes nesses países.

A situação dos direitos humanos é agravada nos dias atuais, em que 0 fenômeno da globalização aumenta a miséria em todo o planeta, especialmente nos países em desenvolvimento, como é o caso do Brasil e dos demais membros do Mercosul, fato que corrobora a posição aqui defendida, de uma união desses países em prol da promoção da dignidade dos indivíduos. Assim em Nádia de Araújo e Inês da Matta Andreiuolo: "quanto aos países do terceiro mundo, esse processo [globalização] parece trazer mais problemas do que vantagens, pois há uma diminuição de sua capacidade do acesso às tecnologias de ponta e o aumento dos processos de exclusão social. Por isso,

${ }^{25}$ PIOVESAN, F. Direitos Humanos e o Direito Constitucional Internacional, p. 239.

Revista Brasileira de Direito Internacional, Curitiba, v.3, n.3, jan./jun.2006 
podem vislumbrar a possibilidade de uma consciência normativa comum, ancorada na idéia dos direitos humanos"26.

Não apenas no que tange à promoção dos direitos humanos, mas principalmente na garantia de proteção efetiva, a cooperação interestatal é mais que necessária. Com efeito, é cada vez mais transparente a "resistência dos tribunais e de outras esferas governamentais em incorporar as normas internacionais previstas nos tratados de direitos humanos" ${ }^{27}$, sob a tão alegada defesa da soberania. Essa problemática por si só já demonstra o quão insuficiente é buscar solucionar as questões de direitos humanos somente por meio da assinatura de tratados. Os Estados sozinhos não têm se empenhado (quiçá conseguido) garantir um mínimo de dignidade a seus cidadãos, o que reforça a necessidade de um esforço internacional nesse sentido, de monitoramento do respeito aos direitos humanos, algo que o sistema interamericano não tem logrado resultados eficazes (a despeito das diversas decisões e recomendações, em número, entretanto, muito reduzido se comparado à realidade latino-americana).

Tem-se muito claro, no entanto, a dificuldade enorme que existe na implementação dos objetivos iniciais do Mercosul, mormente no que concerne a qualquer tipo de regulamentação comum. Segundo Paulo Borba Casella, "a proliferação de normas internacionais (...) não se fez acompanhar pelo correspondente desenvolvimento do processo judicial internacional ou dos correspondentes mecanismos para a execução de normas internacionais, assistindo-se antes à regressão do que ao progresso nesse tópico"28. Pode-se pensar, então, que se dentro da atual conjuntura do Mercosul já se torna muito difícil garantir efetividade à normatividade regional, inserir a proteção dos direitos humanos nesse contexto talvez não fosse adequado, sob pena de não se conseguir o resultado esperado.

Mas já há uma experiência no mundo que permite afirmar e defender a conveniência dessa conjugação de esforços entre os países do Mercosul e o

\footnotetext{
${ }^{26}$ ARAÚJO, Nádia de; ANDREIULO, Inês da Matta. A internalização dos Tratados no Brasil e os Direitos Humanos, p. 65.

${ }^{27}$ CENTRO DE JUSTIÇA GLOBAL. Programa de Capacitação "Márcio Baccarin Possebom": treinamento em mecanismos internacionais de direitos humanos e estratégias de mídia, p. 5.

${ }^{28}$ CASELLA, Paulo Borba. Mercosul: exigências e perspectivas, p. 209.
}

Revista Brasileira de Direito Internacional, Curitiba, v.3, n.3, jan./jun.2006 
Sistema Interamericano de Direitos Humanos, guardadas as devidas proporções. No âmbito europeu, o cumprimento das decisões e recomendações provindas do sistema europeu de direitos humanos é reforçado pela exigência da União Européia de que seus membros promovam o respeito e a proteção dos direitos do homem. Considerando-se sempre que os objetivos da integração européia são distintos dos objetivos do bloco do Mercosul, a experiência do Velho Continente é de grande valia para que algo semelhante possa ser instituído aqui.

E essa ampliação dos objetivos do Mercosul para abarcar também a proteção aos direitos humanos pode começar traduzindo-se inicialmente na exigência de que seus integrantes sejam signatários da Convenção Americana de Direitos Humanos e que tenham reconhecido expressamente a competência da Corte Interamericana para julgar as violações aos direitos humanos em seus territórios. No presente, isto já acontece, pois tanto os membros do bloco quanto os associados cumprem esses requisitos. Mas é uma exigência útil em caso de admissão de novos membros.

Outra forma de o Mercosul cooperar para a efetividade do sistema interamericano seria a instituição, dentro do Foro Consultivo Econômico e Social, de um órgão de monitoramento de direitos humanos, com a finalidade de compelir os Estados ao cumprimento das recomendações da Comissão e das decisões da Corte, em tempo razoável e de forma a amparar os direitos das vítimas. Para isso, o Foro necessitaria de uma reformulação, porque ele possui caráter apenas consultivo, e seus pareceres não vinculam nem os Estados e nem os demais órgãos do Mercosul. Se a competência do Foro fosse alargada dessa maneira, poderia haver inclusive a cominação de sanções econômicas aos países com reiteradas recomendações e decisões não cumpridas, ou diante de situações de violações sistemáticas de direitos humanos.

Uma terceira possibilidade de assegurar a efetividade do sistema interamericano nos países do Mercosul é a edição de uma legislação comum para o cumprimento das sentenças internacionais de direitos humanos. A uniformização dessa matéria é mais uma garantia de respeito às medidas 
determinadas pela Comissão e pela Corte para minimizar o sofrimento das vítimas. Esse assunto é parcamente tratado pela Convenção Americana, que em seu artigo 68.2 apenas se refere à execução das sentenças indenizatórias, que deve se dar da mesma forma que as sentenças dessa natureza nos ordenamentos internos. Mas, na linha de André de Carvalho Ramos, "a reparação em sentido amplo pode ser concretizada sob várias espécies, sendo a indenização apenas uma delas. Logo, as outras medidas reparatórias nãopecuniárias dependerão exclusivamente dos mecanismos internos, sendo a sentença internacional meramente declaratória" ${ }^{\text {"29 }}$. Por mais que se alegue que a emergência de uma legislação uniforme nessa matéria possa ferir a soberania dos países, e que se a Convenção preferiu não tratar do tema é porque aqui se verificaria a subsidiariedade do direito internacional, basta um olhar para a realidade dos direitos humanos na América Latina, e em especial nos Estados-membros do Mercosul, para que se perceba a insuficiência dessas afirmações e a urgência de um meio mais eficaz para compelir os Estados à garantia da efetividade dos mecanismos do sistema interamericano.

Se se efetivassem essas modificações, e outras que assegurassem a cooperação entre Mercosul e o Sistema Interamericano, seria possível, inclusive, que esses países propugnassem juntos pelas reformas mais que necessárias na Comissão e na Corte, com uma força certamente maior do que teriam se buscassem essas mudanças sozinhos.

Do exposto acima, infere-se a necessidade, senão urgência, de que o Mercosul interfira na garantia de efetividade às recomendações da Comissão e às decisões da Corte Interamericana de Direitos Humanos. No que tange à proteção da pessoa humana, considerações de defesa absoluta da soberania estatal não podem servir de justificativa para que se caminhe em sentido oposto a este.

${ }^{29}$ RAMOS, André de Carvalho. Processo internacional de Direitos Humanos, p. 331.

Revista Brasileira de Direito Internacional, Curitiba, v.3, n.3, jan./jun.2006 


\title{
5 CONCLUSÃO
}

O memorável internacionalista Celso Duvivier de Albuquerque Mello certa vez assim escreveu:

\begin{abstract}
"neste final de século e início do século XXI em que o neocapitalismo assume uma de suas fases mais selvagens (...), só nos resta o ser humanos na sua mais fantástica nudez, isto é, independentemente de cor, religião, orientação política, etc. O Direito Internacional dos Direitos Humanos visa ao homem pelo homem e para o homem. Os Direitos Humanos têm sido defendidos como a única ideologia da época em que vivemos (...) ${ }^{30}$.
\end{abstract}

É com esse pensamento que este artigo foi concebido. É no intuito de se maximizar a proteção internacional dos direitos humanos que o presente trabalho propõe que o Mercado Comum do Sul, porque engloba países com realidades muito semelhantes, preocupe-se também com a promoção desses direitos. Apesar de se ter em mente que os objetivos do bloco, tal como estruturado até o momento, referem-se a aspectos de integração econômica e comercial, é inegável que os cidadãos desses Estados-membros somente teriam a ganhar se a proteção aos direitos da pessoa humana fosse erigida ao nível de preocupação regional.

É claro que esse assunto não se esgota em um simples artigo. $O$ escopo fundamental era o de fomentar o debate sobre a efetividade da normatividade internacional de direitos humanos, e possíveis meios para assegurar que tais mecanismos não se tornem mero aparato teórico, inacessível e dispensável à população que dele necessita. Concordamos com a afirmação de que:

\footnotetext{
"a existência de tribunais internacionais com competência para julgar Estados que violem direitos de seus habitantes, direitos estes previstos em Convenção Internacional por eles ratificada representa uma significativa evolução na efetiva implementação dos mínimos direitos essenciais à sobrevivência da
}

${ }^{30}$ MELLO, Celso Duvivier de Albuquerque. Curso de Direito Internacional Público, p. 784.

Revista Brasileira de Direito Internacional, Curitiba, v.3, n.3, jan./jun.2006 
civilização e requisito para uma vida digna e não meramente uma sobrevida" ${ }^{31}$.

Entretanto, é preciso que se encontrem meios de fazer com que esses direitos sejam realmente aplicados no plano prático, e a sugestão deste trabalho é apenas uma das maneiras de se permitir que isso ocorra.

\section{REFERÊNCIAS}

ACCIOLY, Elizabeth. Mercosul e União Européia: estrutura jurídicoinstitucional. 3.ed. Curitiba: Juruá, 2004.

ARAÚJJO, Nádia de; ANDREIUOLO, Inês da Matta. A internacionalização dos tratados no Brasil e os direitos humanos. In: BOUCAULT, Carlos Eduardo de Abreu; ARAÚJJ, Nádia de (orgs.). Os direitos humanos e o direito internacional. Rio de Janeiro: Renovar, 1999, p. 63-113.

BAPTISTA, Luiz Olavo. O Mercosul, suas instituições e ordenamento jurídico. São Paulo: LTr, 1998.

CANÇADO TRINDADE, Antônio Augusto. A personalidade e capacidade jurídicas do indivíduo como sujeito do direito internacional. In: ANNONI, Danielle (org.). Os Novos Conceitos do Novo Direito Internacional: cidadania, democracia e direitos humanos. Rio de Janeiro: América Jurídica, 2002, p. 0131.

. A proteção internacional dos direitos humanos: fundamentos jurídicos e instrumentos básicos. São Paulo: Saraiva, 1991.

CASELLA, Paulo Borba. Mercosul: exigências e perspectivas: integração e consolidação de espaço econômico (1995 - 2001 - 2006). São Paulo: LTr, 1996.

CENTRO DE JUSTIÇA GLOBAL. Programa de Capacitação "Márcio Baccarin Possebon": treinamento em mecanismos internacionais de direitos humanos e estratégias de mídia. Rio de Janeiro/São Paulo: Centro de Justiça Global, 2002.

FIORATI, Jete Jane; BREVIGLIERI, Etiene. Direitos Humanos e jurisprudência internacional. In: ANNONI, Danielle (org.). Os Novos Conceitos do Novo Direito

${ }^{31}$ FIORATI, J. J.; BREVIGLIERI, E. Direitos humanos e jurisprudência internacional, p. 294.

Revista Brasileira de Direito Internacional, Curitiba, v.3, n.3, jan./jun.2006 
Internacional: cidadania, democracia e direitos humanos. Rio de Janeiro: América Jurídica, 2002, p. 277-294.

FRIEDRICH, Tatyana Scheila. Sistema Interamericano de Proteção de Direitos Humanos: a Comissão e a Corte Interamericana de Direitos Humanos. Revista da Faculdade de Direito da Universidade Federal do Paraná. Porto Alegre: Síntese, v.33, p. 261-274, 2000.

MELLO, Celso Duvivier de Albuquerque. Curso de Direito Internacional Público. Rio de Janeiro: Renovar, 2003.

ORGANIZAÇÃO DOS ESTADOS AMERICANOS/COMISSÃO INTERAMERICANA DE DIREITOS HUMANOS (orgs.). Como apresentar petições no sistema interamericano. Washington: Comissão Interamericana de Direitos Humanos, 2003.

PIOVESAN, Flávia. Direitos Humanos e o Direito Constitucional Internacional. 6.ed. São Paulo: Max Limonad, 2004.

QUESADA POLO, Santiago. El convenio europeo de derechos humanos. In: Documentary File. v.2. Allée René Cassin: Strasbourg, 2000.

RAMOS, André de Carvalho. Processo Internacional de Direitos Humanos: análise dos sistemas de apuração de violações de direitos humanos e a implementação das decisões no Brasil. Rio de Janeiro/São Paulo: Renovar, 2002. 